\title{
Probiotics in treating diseases - short review
}

\author{
Maria DRAGAN ${ }^{1}$, Diana POPOVICl${ }^{2}$, Ruxandra Teodora STAN ${ }^{3}$, Catalina Daniela STAN ${ }^{1}$ \\ ${ }^{1}$ Department of Drug Industry and Pharmaceutical Biotechnology, Faculty of Pharmacy, \\ "Gr.T. Popa" University of Medicine and Pharmacy, lasi, Romania \\ ${ }^{2}$ Department of Mother and Child Medicine, Faculty of Medicine, "Gr.T. Popa" University of Medicine and \\ Pharmacy, lasi, Romania \\ ${ }^{3}$ Faculty of Dental Medicine, "Gr.T. Popa" University of Medicine and Pharmacy, Iasi, Romania
}

\begin{abstract}
In the last 20 years, probiotics have attracted specialists attention being conducted over 50 studies investigating the probiotics use in human diseases treatment. These studies revealed that the probiotics potential is ranging from constipation to hepatic encephalopathy. Probiotics are able to normalize the intestinal microbial ecosystem, to improve the gut barrier function, to inhibit potential pathogens and to modulate the immune and anti-inflammatory activities. Further studies need to clarify the optimal effective dosage for specific diseases, the most effective probiotic for distinctive diseases, to emphasize the interactions with food, and to determine if single-species probiotics would provide helth benefits.
\end{abstract}

Keywords: probiotics, lactobacilli species, bifidobacteria species, microbiome

\section{INTRODUCTION}

During the '70s-'80s years, researchers from Yale laboratories demonstrated that there is a relationship between the intestinal bacteria and substances (foods, liquids, medicines) that entered the digestive tract. Afterwards, the specialists realized the importance of the microbiota and thus, the Human Microbiome Project was developed [1]. This project gathers data about human microbiota and the nutrients that feed these organisms. The microbiome is very dynamic and it can be changed by different amounts of prebiotics or dietary fiber. Depending on this, the ingestion of different nutrients (prebiotics, dietary fiber etc.) stimulates the growth of some beneficial bacteria.

The human microbiome consists principally of diverse bacteria, but also there are present fungi, viruses, archaea and protozoans. All these species together are known as commensal microbiota. In the human colon it can be found about 1000-1500 distinct species, specialists estimate that each person has almost 160 species [2]. Several studies established that probiotics administered in daily doses of 108-1010 colony-forming units (CFU) improve the general health of humans [3].

Probiotics includes Lactobacillus species ( $L$. rhamnosus GG, L. reuteri, L. casei, L. paracasei), Bacillus species (B. coagulans, B. clausii), Bifidobacterium species (B. infantis, B. longum, B. bifidum), Saccharomyces species (S. boulardii, S. cerevisiae), Streptococcus thermophiles and Escherichia coli Nissle 1917. Usually, probiotics are mixtures of several species [3].

The probiotic market has exceeded US 37.7 billion dollars in 2016, claiming over 100 distinct benefits $[3,4]$. On the opposite side the Food and Drug 
Administration (FDA) stated: "To date, the U.S. FDA has not approved health claims for any probiotic", proving that FDA, but also European Medicines Agency, are essentially focused and interested in probiotics safety, quality and efficacy. [5].

\section{BENEFITS OF PROBIOTICS}

Probiotics (beneficial bacteria, good bacteria) are live microorganisms involved in maintaining human health, ranging from improving nutrient absorption to preventing cancer and cardiovascularrelated diseases. Thereby, probiotics are widely studied through basic and clinical research, taking into account the increasing use of nutritional supplements and pharmaceutical products.

Intestinal dysfunctions are due to disruption of the colonic flora (due to the antibiotic use, diseases, pathogens etc.), dietary antigens, ingestion of the harmful substances etc. Probiotics prevent enteropathogenic infections by several mechanisms: decreasing the luminal $\mathrm{pH}$; blocking the supply of the pathogens with nutrients; producing compounds with inhibitory action [6].

Studies showed that some probiotics, like lactobacilli and bifidobacteria species, can inhibit

TABLE 1. Probiotic reported efficacy

\begin{tabular}{|c|c|c|}
\hline $\begin{array}{l}\text { Crt. } \\
\text { no. }\end{array}$ & Condition & Probiotic \\
\hline 1 & Abdominal pain in children & Various \\
\hline 2 & Antibiotic-associated diarrhea & Bifidobacterium \\
\hline 3 & Blood glucose in type II diabetes mellitus & Various \\
\hline 4 & Constipation & Lactobacillus, Bifidobacillus \\
\hline 5 & Halitosis & Lactobacillus \\
\hline 6 & Helicobacter pylori eradication & Various \\
\hline 7 & Hepatic encephalopathy & Various \\
\hline 8 & Infant colic & Lactobacillus reuteri \\
\hline 9 & Infection risk in the critically ill & Various \\
\hline 10 & Irritable bowel syndrome & $\begin{array}{l}\text { Saccharomyces cerevisiae, } \\
\text { Bifidobacterium infantis }\end{array}$ \\
\hline 11 & Late-onset sepsis in preterm infants & Various \\
\hline 12 & $\begin{array}{l}\text { Prevention of C. difficile infections in } \\
\text { hospitalized patients }\end{array}$ & Various \\
\hline 13 & Prevention of necrotizing enterocolitis & Various \\
\hline 14 & Prevention of radiation-associated diarrhea & $\begin{array}{l}\text { Lactobacillus, Bifidobacterium } \\
\text { bifidum }\end{array}$ \\
\hline 15 & Small intestinal bacterial overgrowth & Various \\
\hline 16 & Surgical site infections & Synbiotic \\
\hline 17 & Total choleresterol and LDL-cholesterol lowering & $\begin{array}{l}\text { Lactobacillus reuteri, } \\
\text { Lactobacillus plantarum }\end{array}$ \\
\hline 18 & Ulcerative colitis & Various \\
\hline
\end{tabular}

some enteropathogenic species based on an inhibitory mechanism [6]. Other studies revealed that probiotics act by altering the microbiome function and modulate the immune response [7]. Today it is well known that some probiotics have shown promise in prevention and treatment of diseases in which aberrant microbiota have been reported, such as: infectious diarrhoea, allergy, cancer, inflammatory bowel disease, irritable bowel syndrome [8].

The efficacy of probiotics reported by studies and meta-analysis are shown in Table 1 [3].

\section{PROBIOTICS RISKS}

Even though the health benefits of probiotics are well known, the risks are too little acquainted. One of them is that antibiotic-resistant determinants carried by probiotics can be transferred to opportunistic pathogens thus increasing resistance $[9,10]$. Previous in vitro and in vivo studies highlighted the transfer between probiotics or between probiotics and pathogens of genes involved in antibiotic resistance $[11,12]$. Also, it is certain that some probiotics (mainly Lactobacillus) are not stable (are degraded) in the presence of acids and bile salts [10]. In order to increase their stability, while transiting the gastrointestinal tract, in commercial probiotic supplements with strains of Lactobacillus are added buffers (saccharides, proteins) which will keep the $\mathrm{pH}$ within a range. Moreover, for the industrial obtaining it is used encapsulation as technology in order to promote stability and survivability for this species [13-15]. Some of the probiotics side effects include gas, abdominal bloating, metabolic disorder, abnormal immune response, D-lactate encephalopathy and mental processes disorder [16-19]. 


\section{PROBIOTICS IN DISEASES}

\section{Infectious diarrhoea}

Enteric and diarrhoeal disease usually has viral origin, and occurs when there is no access to safe water, to sanitary facilities and also personal hygiene is poorly. It leads to acute/chronic undernutrition, deficits in growth and cognition. Also, it causes morbidity and mortality among children.

Several studies evaluated their efficacy concluding that treatments with probiotics reduce diarrhoea duration by about one day. There were investigated strains of Saccharomyces boulardi and Lactobacillus rhamnosus $G G$, reported data showing that the frequency of diarrhoea episodes is reduced by $50 \%$. Also, investigation of Bifidobacterium infantis and Streptococcus thermophiles, which were added in infant formula, proved to reduce the frequency of acute infectious diarrhoea [20]. Despite all these data, for critically ill patients there is no probiotics recommendation.

\section{Inflammatory bowel disease}

Regardless of the great expectations, no effects were recorded for probiotic treating Crohn's disease. Instead, for ulcerative colitis with mild to moderate symptoms a combination of Lactobacillus, Bifidobacterium, Streptococcus, Escherichia coli strain Nissle 1917 probiotics benefits were described. Also, studies revealed that dietary strategies are alternative treatments to enhance the human microbiome function or decrease the pathogens activities in order to provide a better healthy state in inflammatory bowel disease [21, 22].

\section{Irritable bowel syndrome}

Irritable bowel syndrome (IBS) is a chronic gastrointestinal disorder with a diversity of symptoms like abdominal pain, bloating, distension, bowel movements, diarrhoea, constipation, also anxiety, depression and other symptoms unrelated to the intestine. There are studies suggesting that patients with IBS present enteric microbiota alterations that affect normal brain functions and signaling leading to neurological disorders, the gut-brain axis being a new concept. Several metaanalyses concluded that probiotics, like lactic acid bacteria, Bifidobacterium bifidum, have benefits in treating IBS [23, 24, 25].

\section{Cancer therapy}

In the top three cancers is colorectal cancer one of the most common cancers globally. Age, smoking, diet, genetic mutations and other risk factors lead to colorectal cancer. The newest scientific breakthrough suggested that specific alteration in human microbial metabolism is related to colorectal cancer, but the oncogenic mechanism is not yet known. However, many scientists state that on precancerous lesions probiotics proved to have beneficial effects, potential mechanisms described in literature include enteric $\mathrm{pH}$ modification, colonic inflammation decrease etc. [26,27]. A japanese study suggests that after 4 years of Lactobacillus casei administration the development of the colorectal tumors was prevented [28]. Other studies point out that probiotics daily intake has shown an improvement in the health status of patients with colorectal tumors treated with chemotherapy or radiation $[29,30]$.

\section{Allergy}

It is well known that bacterial dysbiosis are closely related with allergic disorders. Even if several studies have been reported clinical improvements in atopic dermatitis when probiotics were used $[31,32]$, nevertheless the probiotics efficacy has not been yet proved in such allergic disorders [33]. Also, no benefits were recorded on asthma and allergic rhinitis therefore recommendation of probiotics remains empirical and not based on scientific evidence.

\section{CONCLUSIONS}

Probiotics are promising supplements in order to prevent several important diseases, but further validation studies are needed. It is important to underline their clinical properties for a better acceptance by the patients.

Probiotics were found to be beneficial in infantile colic, acute infectious diarrhoea, inflammatory bowel syndrome and in reducing infections, with no severe adverse events recorded, being safer than most pharmaceuticals.

Potential risks are associated with probiotics therefore human intake of probiotics must be supervised by health professionals. 


\section{REFERENCES}

1. Floch MH. Probiotics and Prebiotics. Gastroenterol Hepatol. 2014;10(10):680-681.

2. Lloyd-Price J, Abu-Ali G, Huttenhower C. The healthy human microbiome. Genome Med. 2016;8:51-59.

3. Liu Y, Tran DQ, Rhoads JM. Probiotics in Disease Prevention and Treatment. J Clin Pharmacol. 2018;58(10):S164-S179.

4. ***. Global probiotics market forecast 2017- 2025. Inkwood Research Publisher, 2017.

5. ${ }^{* * *}$. Safety of probiotics to reduce risk and prevent or treat disease: Executive Summary. Evidence-Based Practice. Agency for Healthcare Research and quality (AHRQ), http://www.ahrq.gov/ sites/default/files/publications/files/probiotsum.pdf.

6. Fooks LJ, Gibson GR. In vitro investigations of the effect of probiotics and prebiotics on selected human intestinal pathogens. FEMS Microbiology Ecology. 2002;39:67-75.

7. Sanders ME, Guarner F, Guerrant R, Holt PR, Quigley EMM, Sartor RB, Sherman PM, Mayer EA. An update on the use and investigation of probiotics in health and disease. Gut Microbes. 2013;62(2):787-796.

8. Liu J, Wan G, Huang M, Agyapong G, Zou T, Zhang X, Liu YW, Song Y, Tsai YC, Kong X. Probiotic Therapy for Treating Behavioral and Gastrointestinal Symptoms in Autism Spectrum Disorder: A Systematic Review of Clinical Trials. Current Medical Science. 2019;39:173-184.

9. Broaders E, Gahan CG, Marchesi, JR. Mobile genetic elements of the human gastrointestinal tract: potential for spread of antibiotic resistance genes. Gut Microbes. 2013;4:271-280.

10. Wang $Y$, Jiang $Y$, Deng $Y$, Yi C, Wang Y, Ding $M$, Liu J, Jin $X$, Shen L, He Y, Wu X, Chen X, Sun C, Zheng M, Zhang R, Ye H, An H, Wong A. Probiotic Supplements: Hope or Hype? Front Microbiol. 2020.

11. Mater DD, Langella P, Corthier G, Flores MJ. A probiotic Lactobacillus strain can acquire vancomycin resistance during digestive transit in mice. J Mol Microb Biotech. 2008;14:123-127.

12. Thumu SCR, Halami PM. Conjugal transfer of erm(B) and multiple tet genes from Lactobacillus spp. to bacterial pathogens in animal gut, in vitro and during food fermentation. Food Res Int. 2019;116:1066-1075.

13. Wang RM, Li N, Zheng K, Hao JF. Enhancing acid tolerance of the probiotic bacterium Lactobacillus acidophilus NCFM with trehalose. FEMS Microbiol Lett. 2018;365:fny217.

14. Corcoran BM, Stanton C, Fitzgerald GF, Ross RP. Survival of probiotic lactobacilli in acidic environments is enhanced in the presence of metabolizable sugars. Appl Environ Microbiol. 2005;71:3060-3067.

15. Gbassi GK, Vandamme T. Probiotic encapsulation technology: from microencapsulation to release into the gut. Pharmaceutics. 2012;4:149-163.

16. Zmora N, Zilberman-Schapira G, Suez J, Mor U, Dori-Bachash M, Bashiardes $S$ et al. Personalized gut mucosal colonization resistance to empiric probiotics is associated with unique host and microbiome features. Cell. 2018;174:1388-1405.

17. Lerner A, Matthias T, Aminov R. Potential effects of horizontal gene exchange in the human gut. Front Immunol. 2017;8:1630.
18. Lerner A, Shoenfeld Y, Matthias T. Probiotics: if it does not help it does not do any harm. Really? Microorganisms. 2019;7:104.

19. Kothari D, Patel S, Kim SK. Probiotic supplements might not be universally-effective and safe: a review. Biomed Pharmacother. 2019;111:537-547.

20. Saavedra JM, Bauman NA, Oung I, et al. Feeding of Bifidobacterium bifidum and Streptococcus thermophilus to infants in hospital for prevention of diarrhoea and shedding of rotavirus. Lancet. 1994;344:1046-1049.

21. Whitehead KJ, Schmitz JM, Carroll I, et al. Ingestion of dietary carbohydrates influences the aggressiveness of colitis and intestinal microbial composition in IL-10 mice. Gastroenterology. 2011;138:A51.

22. Matsuura M, Liu B, Carroll I, et al. Selective alteration of growth and virulence for iron-dependent bacterial species; Possible novel mechanisms of detrimental effects of dietary iron on intestinal inflammation. Gastroenterology. 2011;138:A734.

23. Clarke G, Cryan JF, Dinan TG, et al. Review article: probiotics for the treatment of irritable bowel syndrome - focus on lactic acid bacteria. Aliment Pharmacol Ther. 2012;35:403-413.

24. O'Mahony L, McCarthy J, Kelly P, et al. Lactobacillus and bifidobacterium in irritable bowel syndrome: symptom responses and relationship to cytokine profiles. Gastroenterology. 2005;128:541-551.

25. Whorwell PJ, Altringer L, Morel J et al. Efficacy of an encapsulated probiotic Bifidobacterium infantis 35624 in women with irritable bowel syndrome. Am J Gastroenterol. 2006;101:1581-1590.

26. Zhu Y, Michelle Luo T, Jobin C et al. Gut microbiota and probiotics in colon tumorigenesis. Cancer Lett. 2011;309:119-127.

27. Azcarate-Peril MA, Sikes M, Bruno-Barcena JM. The intestinal microbiota, gastrointestinal environment and colorectal cancer: a putative role for probiotics in prevention of colorectal cancer? Am J Physiol Gastrointest Liver Physiol. 2011;301:G401-G424.

28. Ishikawa H, Akedo I, Otani T, et al. Randomized trial of dietary fiber and Lactobacillus casei administration for prevention of colorectal tumors. Int J Cancer. 2005;116:762-767.

29. Osterlund P, Ruotsalainen T, Korpela R, et al. Lactobacillus supplementation for diarrhoea related to chemotherapy of colorectal cancer: a randomised study. Br J Cancer. 2007;97:10281034.

30. Chitapanarux I, Chitapanarux T, Traisathit P, et al. Randomized controlled trial of live lactobacillus acidophilus plus bifidobacterium bifidum in prophylaxis of diarrhea during radiotherapy in cervical cancer patients. Radiat Oncol. 2010;5:31-38.

31. Shane AL, Cabana MD, Vidry S, et al. Guide to designing, conducting, publishing and communicating results of clinical studies involving probiotic applications in human participants. Gut Microbes. 2010;1:243-253.

32. Folster-Holst R. Probiotics in the treatment and prevention of atopic dermatitis. Ann Nutr Metab. 2010;57:16-19.

33. Ozdemir O, Goksu Erol AY. Preventative and therapeutic probiotic use in allergic skin conditions: experimental and clinical findings. Biomed Res Int. 2013;2013:932391. 